\title{
Scintimammography - Molecular Imaging: Value and New Perspectives with ${ }^{99 \mathrm{~m}} \mathrm{Tc}(\mathrm{V})$-DMSA
}

\author{
Vassilios Papantoniou, Pipitsa Valsamaki and Spyridon Tsiouris \\ University General Hospital "Alexandra", Athens
}

Greece

\section{Introduction}

Breast cancer is the most common non-skin cancer and the second leading cause of cancer death in women. Despite advances in the adjuvant treatment of early stage disease, many women will have breast cancer relapse that often is not amenable to complete surgical excision [Eubank et al., 2005]. There are 40,000 women per year dying of breast cancer in the United States, and most breast cancer victims die of progressive metastatic disease.

Currently, the detection and staging of breast cancer involves physical examination, fine needle aspiration (FNA) biopsy and imaging methods, namely mammography, ultrasonography, breast magnetic resonance imaging (MRI) and scintimammography. Screening mammography is widely available and evaluates patients with low cost, yet it bears a sensitivity ranging from $45 \%$ to $90 \%$ and low specificity, especially in cases of dense breasts, fibrocystic change and scars. Ultrasonography differentiates cystic from solid masses. Scintimammography by the use of various common radiotracers such as technetium-99m hexakis 2-methoxyisobutyl isonitrile (99mTc-sestamibi), 99mTc-6,9-bis (2ethoxyethyl)-3, 12-dioxo-6, 9-diphosphatetradecane (99mTc-tetrofosmin), thallium-201 chloride $\left({ }^{201} \mathrm{TlCl}\right), 99 \mathrm{mTc}-m e t h y l e n e ~ d i p h o s p h o n a t e ~(99 \mathrm{mTc}-\mathrm{MDP})$ and pentavalent $99 \mathrm{mTc}-$ dimercaptosuccinic acid [99mTc(V)-DMSA], constitutes not only a complementary modality, but a significant method of choice in particular clinical settings, as summarized in Table 1.

Nuclear medicine methods enormously contribute to breast cancer clinical management due to the following reasons: (a) the recent technological advance in the detection and processing systems. Single photon emission computed tomography (SPECT) is progressively used more often in parallel with traditional planar scintigraphy with considerable improvement of the resolution and sensitivity of the scintigraphic image, mainly pertaining to lymph node involvement. The detection limit regarding malignant lesions approaches the corresponding one obtained by traditional radiological methods. Another important innovative improvement is positron emission tomography (PET), a technique which is based on the use of precursor metabolites (amino acids, hormones, monosaccharites), which are labelled with isotopes with very short half life that emit positrons. The pioneer characteristics of this technique enable the study of tumor biology accurately and non-invasively, providing interesting perspectives for research and clinical applications. PET is gradually used more extensively in oncology and seems to have particular value in breast cancer; (b) the introduction of new radiotracers has allowed the 
acquisition of images reflecting on biological and functional parameters that can characterize specific tumor features, like perfusion, mitotic and metabolic activity and receptor status. The significance of these parameters lies upon the fact that apart from defining the extent of the disease, they could also be regarded as prognostic indices of response to treatment and tumor behavior, and thus have major impact on designing and monitoring local and systemic therapy. Among the developed radiopharmaceuticals, the tracers described in Table 2 may play significant role in investigating breast cancer, with particular detection accuracy.

\begin{tabular}{|l|}
\hline Traditional established indications \\
\hline $\begin{array}{l}\text { High-risk patients with difficult mammographic evaluation } \\
\text { (dense breasts, breast structural abnormalities, implants) }\end{array}$ \\
\hline Patients with multiple suspicious lesions or calcifications \\
\hline Lobular carcinoma \\
\hline Scars from previous biopsy visible on mammography \\
\hline Palpable breast mass, not detectable by mammography or ultrasound staging \\
\hline Evaluation of response to pre-operative chemotherapy \\
\hline Detection of residual disease following mastectomy \\
\hline Patients with palpable axillary lymph nodes with unknown primary focus \\
\hline Novel clinical applications for ${ }^{99 m}$ Tc(V)-DMSA [Papantoniou et al., 2006-2011] \\
\hline $\begin{array}{l}\text { Patients with potentially premalignant mammary conditions (pre- and post- } \\
\text { chemopreventive treatment) }\end{array}$ \\
\hline Patients with increased serum CGRP \\
\hline Selection of patients with metastatic breast cancer for treatment with ${ }^{188} \operatorname{Re}(\mathrm{V})$-DMSA \\
\hline
\end{tabular}

Table 1. Indications for scintimammography

\begin{tabular}{|l|l|}
\hline Nuclear medicine modality & Radiopharmaceuticals \\
\hline $\begin{array}{l}\text { Scintimammography: tumor-seeking tracers } \\
\text { with specific metabolic features }\end{array}$ & $\begin{array}{l}\text { 99mTc-sestamibi, } 99 \mathrm{mTc} \text { Tetrofosmin, } \\
\text { 201TlCl }\end{array}$ \\
\hline $\begin{array}{l}\text { Scintimammography: tumor-seeking tracer } \\
\text { with proliferation-seeking properties }\end{array}$ & $\begin{array}{l}\text { 99mTc(V)-DMSA [Papantoniou et al., } \\
\text { Denoyer et al., Al Scheidauer et al.] }\end{array}$ \\
\hline $\begin{array}{l}\text { Hydroxyapatite crystals/amorphous calcium } \\
\text { phosphate-seeking scintigraphy }\end{array}$ & 99mTc-MDP \\
\hline Lymphoscintigraphy & 99mTc-labelled nanocolloids \\
\hline Radioimmunoscintigraphy & Labelled monoclonal antibodies \\
\hline Receptor scintigraphy & $\begin{array}{l}\text { Labelled peptides with affinity for } \\
\text { specific receptors }\end{array}$ \\
\hline PET & 18F-FDG* \\
\hline
\end{tabular}

*18F-FDG: fluorine-18 fluorodeoxyglucose

Table 2. Synopsis of nuclear medicine exams and tracers applied in breast cancer

Furthermore, during the past few years the scintigraphic recognition of mammary lesions retaining a considerable potential to progress to breast cancer has been introduced in association with risk factors involved in the carcinogenic process such as breast density (BD) and calcitonin gene-related peptide (CGRP) [Papantoniou et al. 2010b, 2011]. 


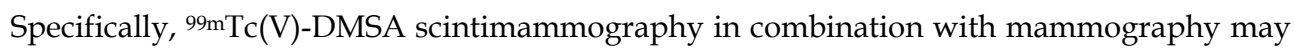
substantially contribute toward the visualization of these lesions [Papantoniou et al. 20052007, 2010, 2011].

Considering that besides cytotoxic chemotherapy, various systemic options including hormonal and other biologically targeted therapies are now available, the detection potential of the imaging modalities currently employed at such early premalignant stages, is limited. Therefore, this review focuses on current and future applications of traditional scintimammography (planar and SPECT) and PET to breast cancer, highlighting the significant advantages, the clinically crucial role and the perspectives of molecular imaging by $99 \mathrm{mTc}(\mathrm{V})$-DMSA scintimammography.

\section{Scintimammography - molecular imaging}

\subsection{Scintimammography with Y-emitting tumor-avid agents}

99m Tc-sestamibi and 99mTc-tetrofosmin are lipophilic cations which accumulate in the cell and in mitochondria due to the negative transmembrane potential. This happens mainly in cells with high-energy metabolism (and hence rich in mitochondria), including neoplastic cells. $99 \mathrm{mTc}$-sestamibi imaging of breast cancer was first reported in a patient under investigation due to myocardial infarction [Chiti A et al., 1994]. As opposed to $99 \mathrm{mTc}$-sestamibi, $99 \mathrm{mTc}-$ tetrofosmin mostly localizes within the cytosol, with only a fraction passing into the mitochondria. Nevertheless, considering that both tracers pass through an intact cell membrane, their cellular uptake and retention mainly reflects on the viability of lesion cells, their perfusion and their metabolic status, including cellular proliferative activity as a major driving force. Moreover, scintimammography using $99 \mathrm{mTc}$-sestamibi/tetrofosmin is not influenced by mammographic limitations, like dense breast and scars. The method demonstrates $85-95 \%$ sensitivity and specificity regarding primary tumor imaging, although somewhat lower values are expected for non-palpable lesions and axillary lymph node invasion. In general, these two tracers present greater sensitivity than ${ }^{201} \mathrm{TlCl}$. The method can help the surgeon localize the tumor during planning biopsy or surgery. In addition, sestamibi is associated with prognostic significance due to the correlation between radiopharmaceutical uptake and tumor angiogenesis or, most importantly, between tumor uptake and tissue P-glycoprotein expression, which is encoded by the multi-drug resistance (MDR) gene. P-glycoprotein is a membrane protein that acts as an ATP-dependent drug efflux pump, excreting anticancer pharmaceuticals and radiopharmaceutical imaging agents outside the tumor cell. Thus, prediction of P-glycoprotein-mediated response to anticancer agents is identified in vivo by sestamibi retention or efflux.

According to the scintimammographic protocol, the patient is asked to accommodate at prone position, in order for anterior, lateral and $30^{\circ}$ posterior oblique images to be obtained. The latter projection is helpful for distinguishing lesions localized at the posterior breast segment from the ones at the thoracic wall and for axillary lesions. The planar images (10min/image) are acquired at 5-10 $\mathrm{min}$ and $60 \mathrm{~min}$ after intravenous (IV) injection of 740 $\mathrm{MBq}$ of radiotracer activity.

${ }^{201} \mathrm{TlCl}$ exhibits kinetic behavior as a potassium-analogue tracer and shows intense uptake in all proliferating cases with increased cell number. Planar scintigraphy, including anterior and lateral images, takes place $3 \mathrm{~h}$ post IV injection of $111 \mathrm{MBq}$ of the tracer. This 
radioligand is indicated in women bearing benign or malignant breast lesions, since it demonstrates a sensitivity of $80-96 \%$. Its specificity varies from relatively poor, with a falsepositive rate of $23 \%$ due to adenomas, to high (96\%) in benign fibrocystic disease, which shows no ${ }^{201} \mathrm{TlCl}$ uptake. Unfortunately, the tracer appears weak in detecting axillary metastases with a reported sensitivity of only $57 \%$. The study seems more suitable in the differential diagnosis of palpable lesions, providing useful indications for the selection of patients for biopsy, rather than pre-operative staging [Waxmann AD et al., 1989, Lee VW et al., 1993]. Of note are the unfavorable radiation characteristics of this tracer when compared to $99 \mathrm{mTc}$-labelled compounds, with increased radiation burden to the patient and inferior image quality.

${ }^{99 m}$ Tc-methylene diphosphonate (MDP) is another radioligand applied in breast lesions and was first proposed by Piccolo $S$ et al. (1995) reporting that a) in a portion of breast lesions MDP uptake with optimal tumor-to-background $(\mathrm{T} / \mathrm{Bg})$ ratio occurs a little after the radiopharmaceutical administration. This phenomenon could be attributed to the particularly increased tumor perfusion due to neo-angiogenesis and c) this it could be useful in the differential diagnosis of mammographically equivocal lesions, or in the diagnosis of lesions in dense breasts, in which mammography shows limited value. Protocol guidelines include image acquisition at anterior and posterior positions at $4 \mathrm{~min}, 10-20 \mathrm{~min}$ and $2 \mathrm{~h}$ post IV injection of $740 \mathrm{MBq}$ of the tracer. Ninety-two percent of breast cancer lesions appear as a focus of 99mTc-MDP uptake in the 10-20 min-image, with mean T/Bg ratio: 4.3 , as opposed to the 2 h-image which is positive in $38 \%$ of cases. In addition, the method provides prognostic information by the traditional whole-body study identifying skeletal metastases.

\subsection{1 ${ }^{99 \mathrm{~m}} \mathrm{Tc}(\mathrm{V})$-DMSA scintimammography}

${ }_{99 m} \mathrm{Tc}(V)-D M S A$ is a well-known tumor-seeking radiotracer with affinity for neuroendocrine and soft tissue tumors, such as medullary thyroid carcinoma and lung, breast, brain, and metastatic bone lesions [Ohta et al., 1984, Babbar et al., 1991, Kashyap et al., 1992, Hirano et al., 1995, Atasever et al., 1997, Lam et al., 1997, Kiratli et al., 1998, Papantoniou et al., 2002, 2004-2007, 2010, 2011, Denoyer et al., 2004, 2005, Tsiouris et al., 2007, Al-Saeedi, 2007]. These tumor-seeking properties have lead to the use of $99 \mathrm{mTc}(\mathrm{V})$-DMSA in scintimammographic studies. In our studies the radiotracer is prepared using a domestically available kit (DMS(V)/Demoscan, National Center of Physical Sciences, Institute of Radioisotopes and Radiodiagnostics "Demokritos", Athens, Greece) labelled with 99mTc within our Department. Scintimammography is performed on a single-head gamma camera (Sophycamera DS7, Sopha Medical Vision International, Buc Cedex, France) equipped with a high-resolution, parallel-hole collimator and connected to a dedicated computer (Sophy NxT, Sopha Medical Vision International). The matrix is set at $256 \times 256$ pixels, and the photopeak centered at $140 \mathrm{keV}$, with a symmetric $10 \%$ window. Lateral and anterior prone early and late planar images (at approximately 10-20 and 60-70 minutes, respectively) are acquired after IV administration of 925 to $1,100 \mathrm{MBq}$ tracer activity. Acquisitions are obtained using a special positioning pad (PBI-2 Scintimammography Pad Set, Pinestar Technology Inc., Greenville, PA). Breast radiotracer uptake in early and late images is first evaluated visually. Any focally increased accumulation is regarded as associated with invasive pathology, whereas any other pattern of a more widespread diffuse uptake has been found to correspond to pre-invasive lesions (ductal carcinoma in situ (DCIS), epithelial 
hyperplasia) [Papantoniou et al., 2005a, 2006a]. Semiquantitative analysis is also performed. Radiotracer uptake area is calculated at the late (60-minute) images by drawing regions of interest (ROI) encompassing the total breast and the area of focally and/or diffusely increased tracer uptake in the lateral view; then the number of pixels within these two regions is divided. The aforementioned procedure is repeated in the anterior scintigraphic image, and the average tracer uptake area of these two views is considered the tracer uptake area of the breast under investigation.

Our research over the last two decades has been increasingly focused on the behavior, kinetics and properties of $99 \mathrm{mTc}(\mathrm{V})$-DMSA in a variety of breast lesions, based on the postulation that breast cancer is the end-result of a continuum, i.e. a pathway leading to malignant transformation upon which intervention possibilities may emerge and early avoid disease development and progression. Therefore this research was initially limited on evaluating invasive ductal carcinoma (IDC) and was continued backwards through the pathway of malignant transformation, i.e. to include DCIS and to reach even some cases of the early stages of epithelial hyperplasia, occasionally representing a state of a so-called "activated" normal epithelium, which could eventually progress to a premalignant state and eventulally to malignant transformation, though lacking such evidence or suspicion on any available imaging modality or even biopsy. Based on in vivo scintigraphic studies, we advocated that its cellular uptake mechanism is closely related to cellular proliferation, as expressed by the Ki-67 immunohistologic index [Papantoniou et al., 2004-2006] and at the same time is independent from estrogen receptor (ER) status [Babbar et al., 1991, Kashyap et al., 1992]. It has been further demonstrated that the uptake of $99 \mathrm{mTc}(\mathrm{V})-\mathrm{DMSA}$ is related to cell proliferation, focal adhesion kinase (FAK) activation, neo-angiogenesis and overexpression of several growth factors, including CGRP and platelet-derived growth factor (PDGF) [Papantoniou et al., 2005-2007, 2010, 2011]. Denoyer and colleagues elucidated the exact mechanisms; notably, the tracer reflects phosphate ion (Pi) transport and metabolism, entering cancer cells specifically via the type III Na/Pi co-transporter, this uptake being driven by the cellular levels of phosphorylated (i.e. activated) FAK, a keystone of accelerated proliferation [Denoyer et al., 2004, 2005].

With reference to the scintimammographic diagnostic yield, we have demonstrated that in cases of clinical and/or mammographic suspicion, both $99 \mathrm{mTc}$-sestamibi and $99 \mathrm{mTc}(\mathrm{V})$-DMSA exhibit high sensitivity (88.4\%), specificity (93.3\%), positive predictive value (PPV) (95\%), negative predictive value (NPV) $(82 \% \& 80 \%)$, and accuracy for the primary lesion (90 \& $89 \%$, respectively). Notably, in lesions of less than $1 \mathrm{~cm}$ in diameter, the planar imaging sensitivity drops to $\sim 75 \%$, a percentage which is considerably improved by SPECT. Regarding lymph node involvement, the tracers have been reported to show $78.9 \%$ sensitivity and $86.3 \%$ specificity. Pre-invasive lesions, like DCIS and lobular carcinoma in situ (LCIS) are detected with high sensitivity by $99 \mathrm{mTc}(\mathrm{V})$-DMSA, whereas with high specificity by 99mTc-sestamibi [Papantoniou et al., 2001, 2002].

Moreover, in breast cancer we have determined tumor size and Ki-67 as independent parameters of $99 \mathrm{mTc}$-sestamibi and $99 \mathrm{mTc}(\mathrm{V})$-DMSA uptake, respectively; hence tumors which accumulate $99 \mathrm{mTc}(\mathrm{V})$-DMSA sustain increased cell proliferation and are in fact more aggressive [Papantoniou et al. 2002].

Relatively recent in vivo and in vitro studies have demonstrated that $99 \mathrm{mTc}(\mathrm{V})$-DMSA possesses the potential to depict increased cellular proliferation, compatible with increased 
Ki-67 expression, not only in IDC (Figure 1) but also in some cases of epithelial hyperplasia of the usual type and in pre-invasive mammary lesions like DCIS, independently of the presence of estrogen or progesterone receptors [Boyd et al., 1998, Papantoniou et al., 20042007, Denoyer et al., 2004, 2005, Tamimi et al., 2007]. Characteristic diffuse and intense $99 \mathrm{mTc}(\mathrm{V})$-DMSA uptake is depicted in a case of usual ductal breast hyperplasia in Figure 2 (a) \& (b), though no corresponding findings are observed by $99 \mathrm{mTc}-$ sestamibi (Figure 2 (c) \& (d)).

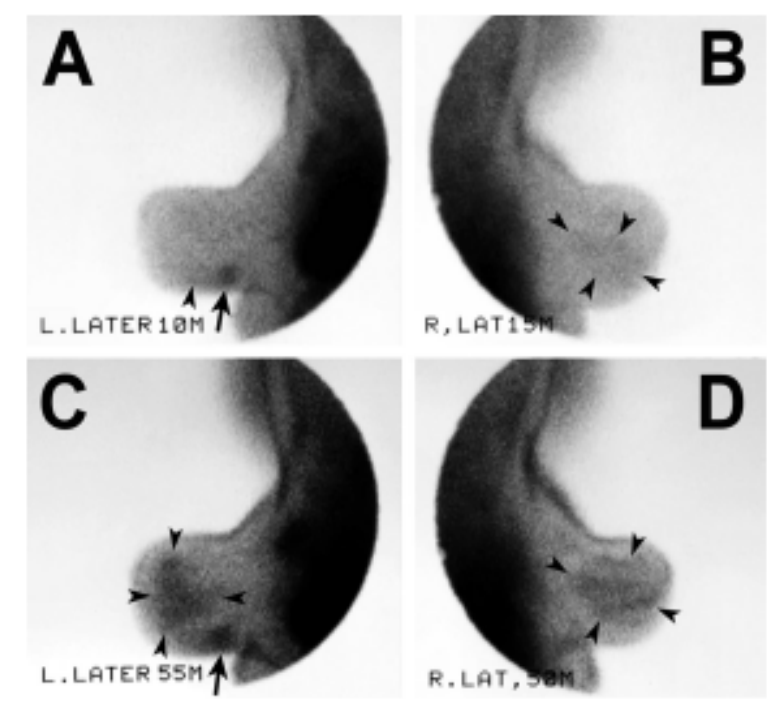

Fig. $1 .{ }^{99 \mathrm{mTc}} \mathrm{T}(\mathrm{V})$-DMSA scintimammography (lateral projections) in a 58-year-old woman bearing a $2.5-\mathrm{cm}$, grade III, left-sided IDC with a coexistent $5-\mathrm{cm}$ DCIS, both diagnosed histologically. A. The round-shaped focal tracer accumulation (arrow) corresponds to the invasive lesion and is noticeable since the early (10-minute) acquisition. Anterior to it lies a restricted, hardly visible region of diffuse tracer uptake (arrowhead). B. On the contralateral breast, there is also a rather faint extended area of diffuse uptake (arrowheads). C. In the late (55-minute) image, the focal ${ }^{99 \mathrm{mTc}} \mathrm{T}(\mathrm{V})$-DMSA accumulation intensifies and its margins expand and become less sharply demarcated from the surrounding breast (arrow). The diffuse tracer uptake, corresponding to the in situ component, substantially increases and extends above and anterior to the invasive lesion, occupying an area of the gland seemingly normal on early imaging. D. Likewise, the inhomogeneous diffuse uptake area on the normal right breast becomes clearer and expands over time. No biopsy for histologic confirmation was performed on this breast; nonetheless, based on our experience from similar histologically-verified scintimammographic patterns, the finding is suspicious of representing a widespread pre-invasive lesion (DCIS and/or epithelial hyperplasia) [Papantoniou et al., 2007].

At the same time, our continuing research shed light to the intensified CGRP expression and neoangiogenesis in IDC with a coexistent in situ and/or hyperplastic component, in association with the tendency of the proliferation depicter ${ }^{99 \mathrm{~m} T c}(\mathrm{~V})$-DMSA to image preinvasive breast pathologies. The CGRP/ ${ }^{99} \mathrm{mTc}(\mathrm{V})$-DMSA correlation could be indicative of 


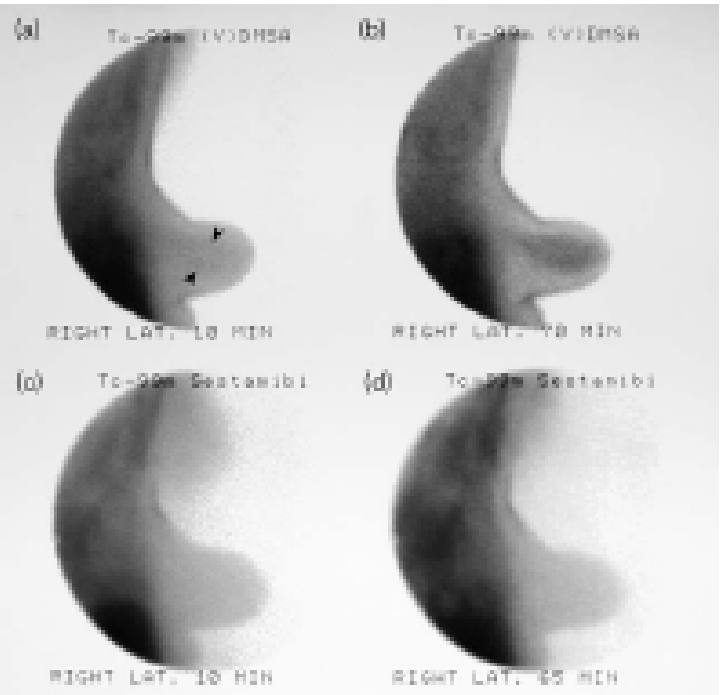

Fig. 2. Dual-tracer study in usual breast hyperplasia. Usual ductal hyperplasia of the right breast in a 68-year-old woman. Scintimammography, right lateral projection; $99 \mathrm{mTc}(\mathrm{V})$-DMSA at (a) $10 \mathrm{~min}$ and (b) $70 \mathrm{~min}$. Diffusely increased tracer uptake in the area corresponding to the lesion is observed, barely visible during early acquisition (arrowheads), but clearly perceptible at 70 min (lesion-to-background ratios: $\mathrm{L} / \mathrm{B}_{\text {early }}=1.32$ and $\mathrm{L} / \mathrm{B}_{\text {late }}=1.83$ ). ${ }^{99 \mathrm{mT}} \mathrm{Tc}$-sestamibi at (c) $10 \mathrm{~min}$ and (d) $65 \mathrm{~min}$. No increased tracer activity is identified in the corresponding area throughout the study $\left(\mathrm{L} / \mathrm{B}_{\text {early }}=1.12\right.$ and $\left.\mathrm{L} / \mathrm{B}_{\text {late }}=1.14\right)$. [Papantoniou et al., 2006b]. As a cell proliferation tracer, ${ }^{99 \mathrm{mTc}}(\mathrm{V}) \mathrm{DMSA}$ evaluates the invasive potential in a case of usual ductal breast hyperplasia, i.e. identifies mammary tissue with increased cellular proliferation, a state of so-called "activated" epithelium, which is related to Ki-67 expression and thus could provide some indication of its probability to progress towards atypical ductal hyperplasia, DCIS and IDC, i.e. the malignant transformation pathway upon which intervention possibilities may aid in early avoidance of disease development and progression.

an additional proliferative role for CGRP, possibly exerted through the PDGF/PDGFreceptor system. In this study, the preferential CGRP expression in low-rather than in highgrade IDC added support to the hypothesis of its precocious role primarily during the early stages of mammary malignant transformation [Papantoniou et al., 2007].

Furthermore, in a recent retrospective study we aimed at identifying a possible relationship between mammographic BD and scintimammographic $99 \mathrm{mTc}(\mathrm{V})$-DMSA uptake in various breast histologies. We also investigated whether women with dense breasts, possibly expressing a proliferative potential, could be discriminated visually or on the basis of semiquantitative analysis of $99 \mathrm{mTc}(\mathrm{V})$-DMSA uptake intensity and benefit from biopsy and possible proper chemoprophylactic treatment. Our findings support that increased BD correlates with the presence of florid epithelial hyperplasia and mixed DCIS+IDC but not with pure IDC or mild epithelial hyperplasia. Its close relationship to the proliferation-

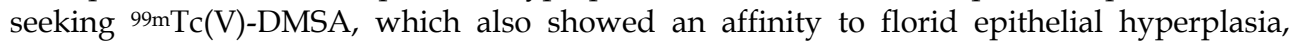
indicates that stromal microenvironment may constitute a specific substrate leading to 
progression to different subtypes of cancerous lesions (i.e. DCIS+IDC) that are totally different from pure IDC originating from particular pathways.

In another prospective study of ours enrolling women with breast epithelial hyperplastic lesions, a relatively short (4-week) scheme of daily oral intake of the non-steroidal antiinflammatory drug (NSAID) ibuprofen $(400 \mathrm{mg})$ resulted in the reduction of diffuse $99 \mathrm{mTc}(\mathrm{V})$-DMSA uptake (Figure 3) [Papantoniou et al., 2010]. Other recent studies have shown that cyclo-oxygenase-2 (COX-2) inhibitors may reduce the risk of breast cancer

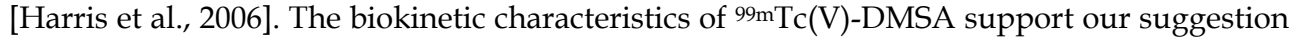
that the observed reduction in its uptake could be attributable to ibuprofen-induced COX inhibition and may indicate a "switch off" mechanism on activated FAK, rather than a slowing down of the proliferation rate per se. ${ }^{99 \mathrm{~m} T c}(\mathrm{~V})$-DMSA cellular uptake is linked to FAK activation and cell proliferation, which is a precocious stage of malignant transformation [Papantoniou et al. 2004, Le Jeune et al. 2005, Al-Saeedi, 2007]. Compared to invasive lesions, the exact mechanism of $99 \mathrm{mTc}-(\mathrm{V}) \mathrm{DMSA}$ accumulation in benign proliferating diseases and in some non-proliferating diseases with higher lesion-tobackground tracer uptake ratios is not yet clear [Papantoniou et al. 2004, 2006b]. Nevertheless, based on the imaging properties and biokinetic characteristics of $99 \mathrm{mTc}(\mathrm{V})-$ DMSA in relation to mammographic density and its ability to visualize potentially preinvasive lesions, the clinical impact of various chemopreventive agents may be evaluated by quantifying their effect on $99 \mathrm{mTc}(\mathrm{V})$-DMSA breast uptake.

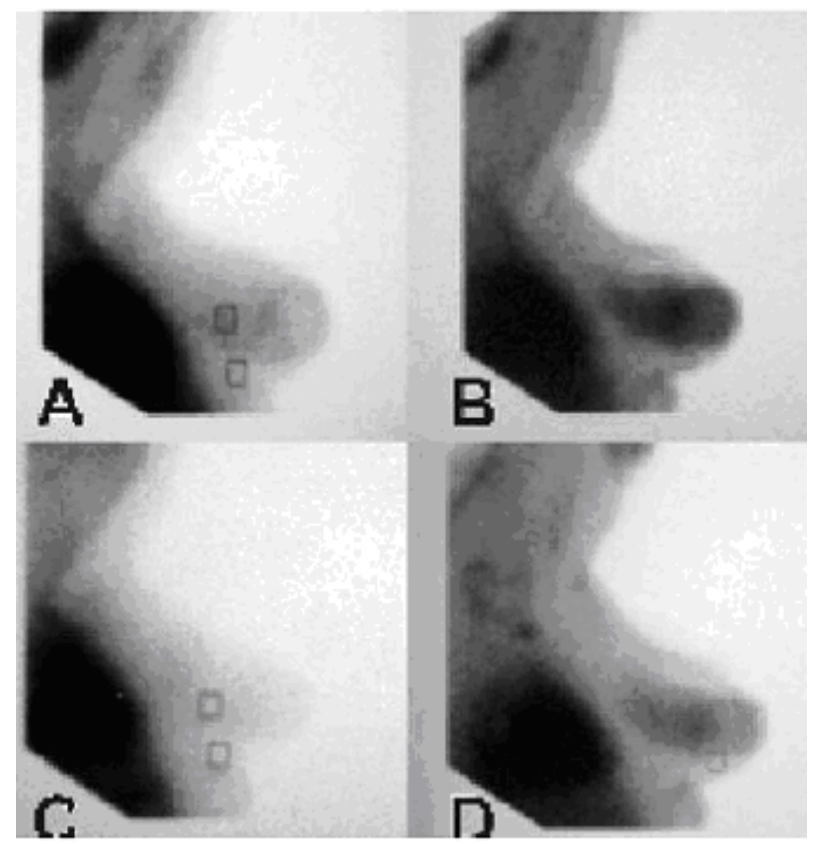

Fig. 3. Early (A) and late (B) images of $99 \mathrm{mTc}(\mathrm{V})$-DMSA breast distribution at baseline and corresponding acquisitions after a monthly oral course of ibuprofen ( $\mathbf{C}$ and $\mathbf{D}$, respectively). After the NSAID treatment the diffuse tracer uptake is notably diminished on both early and late imaging [Papantoniou et al., 2010] 
We also studied prospectively the variation of the serum neo-angiogenic neuropeptide CGRP levels in women bearing histologically confirmed benign and malignant breast lesions and evaluated its possible correlation with mammographic BD. Among the various lesions, including mild, florid and atypical epithelial hyperplasia as well as DCIS and pure IDC, women suffering from mixed DCIS+IDC demonstrated significantly higher serum CGRP levels, which also correlated with BD. These findings further support that DCIS+IDC represents a discrete pathological entity which is evoked by an interdependent mechanism between BD and serum CGRP expression. In addition, in the near future serum CGRP levels could constitute a useful pre-operative index regarding the nature and type of a mammographically suspicious lesion, in order for the proper therapeutic scheme to be planned, and potentially for the challenging innovative perspective of introducing adjunctive therapeutic administration of anti-CGRP peptides.

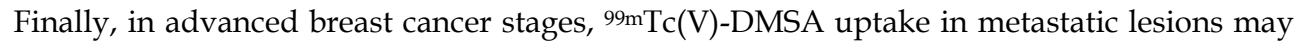
guide therapeutic ${ }^{188} \operatorname{Re}(\mathrm{V})$-DMSA administration, as propounded by Papantoniou and colleagues. Currently this protocol has just started being processed in collaboration with Djokic and colleagues (Vince Institute of Nuclear Sciences, Belgrade, Serbia).

\subsection{Lymphoscintigraphy and lymphoimmunoscintigraphy}

The development of distant metastases and breast cancer patient survival appear to be related to lymphoscintigraphic positivity [Casara et al., 1992, Uren et al., 1995]. Based on the used radiotracers, the following techniques have been applied:

i. Lymphoscintigraphy using labelled colloids. The used radiolabelled particles are 10-30 $\mathrm{nm}$ in size, pass through the extracellular space into the lymph capillaries and are then transferred by the lymph to the regional lymph nodes, to be recruited by macrophages. The colloids used are labelled with ${ }^{99 \mathrm{mTc}}$ and include antimony/sulphur/colloids, b) rhenium/sulphur/microcolloids and c) albumin nanocolloids.

Protocol guidelines indicate injection of $\sim 37 \mathrm{MBq}$ radioactivity in the extracellular space (intradermal, subcutaneous or submucosal) and the injection site depends on the lymph node region under investigation. In breast cancer, the tracer is usually injected in the interdigital spaces of the hand when examining axillary lymph nodes, at the periareolar zone when intramammary lymph nodes are studied, parasternally by the xiphoid process in order for the internal mammary chain to be investigated, or intercostally or close to the tumor.

For over the past decade the strategic importance of the pre-operative determination of lymph node invasion at the mammary region has encouraged the application of lymphoscintigraphy using colloids for lymphatic mapping and detection of the sentinel lymph node (SLN) (100\% PPV and 96\% NPV). Lymphoscintigraphy can be successfully applied in breast cancer management, if conducted intra-operatively by the use of $\gamma$ probe and in combination with blue dye; this technique can identify axillary lymph node invasion and through SLN detection may allow planning strategy and extent of the surgical operation [Krag et al., 1993, De Cicco et al., 1997]. Unfortunately, the method lacks adequate specificity. Therefore, particular attention has been paid to alternative methods: 
ii. Lymphoscintigraphy using tumor-seeking tracers that can localize neoplastic tissue, like 99mTc-sestamibi, which localizes invaded lymph nodes with 80\% PPV and NPV; and

iii. Lymphoimmunoscintigraphy using monoclonal antibodies (MAbs) administered IV, subcutaneously or directly into lymphatics [Khalkhali et al., 2001]. The first lymphoimmunoscintigraphic studies were performed in 1984 and since then various 123/131 I, 111 In or 99mTc-labelled MAbs have been applied, including antibreast MAb (131I-RCC-1), MAbs raised against human milk fat globulins (131I-anti$\mathrm{HMFG}_{1}$, anti-HMFG ${ }_{2}$ ) and anti-carcinoembryonic antigen MAbs ${ }^{99 \mathrm{mTc}-}$ or ${ }^{131} \mathrm{I}-$ labelled anti-CEA, 99mTc-BW 431/26) [Thompson et al., 1984, Athanassiou et al., 1988, Kairemo., 1990]. MAbs approved by the United States Food and Drug Administration (FDA) include the anti-CEA and B72.3, prepared against the tumorassociated glycoprotein- TAG-72. In most cases, breast cancer cell lines produce CEA, although only a slight increase of serum CEA levels above normal may appear [Lind et al., 1991]. Regarding the detection of lymph node breast cancer metastase by arcitumomab, the commercially applied kit of anti-CEA MAb (CEAScan, Immunomedics, Morris Plains, NJ, USA), it has achieved 75\% sensitivity, $83 \%$ specificity, 80\% accuracy, 75\% PPV and 83\% NPV [Nabi, 1997, Goldenberg et al., 1999]. The method has not gained access into routine clinical practice though, because false-positive results are frequent due to tracer uptake by inflammatory lymph nodes, the technique is relatively complex owing to the slow tracer kinetics and biodistribution and the radiolabelled MAbs can hardly be obtained. Nevertheless the inherent biologic property of MAbs to accumulate selectively in the tumor as well as in metastases could be useful in both imaging and treatment of breast cancer. Specifically, "cold" or "hot" monoclonal antibodies may be applied therapeutically, with or without chemotherapeutic agents, thereby propounding significant changes in overall breast cancer management and survival [Stipsanelli et al., 2005]. Hence, further research may assist in most effectively applying lymphoimmunoscintigraphy to aid decision upon conservative or surgical approach, monitoring response to treatment and evaluating treatment regimes.

\subsection{Radioimmunoscintigraphy}

Radioimmunoscintigraphy may play a major role in the diagnosis of multifocal breast cancer by revealing residual or recurrent tumors, and also occult metastases. Several labelled MAbs, already mentioned above, have been hitherto used in breast cancer and new immuno-substrates continue to be proposed. The c-erbB-2 (also known as HER 2 ) oncogene receptor is overexpressed in $25 \%-30 \%$ of breast cancer cell lines and is associated with poor prognosis. The expression of the products of $\mathrm{HER}_{2}$ oncogene in malignant mammary tissue and lymph node metastases has been studied in vivo by radioimmunoscintigraphy using anti-c-erbB-2 oncoprotein MAb labelled with 99mTc and has been targeted by "cold" or "hot" synthetic therapeutic immuno-agents. Specifically, the recombinant humanized "cold" anti$\mathrm{HER}_{2} \mathrm{MAb}$ (or trastuzumab) has been widely used in the United States to treat breast cancer, either alone or combined with chemotherapy. Moreover, radioimmunotherapy comprises systemically administered MAbs, linked to high-energy, beta-emitting radionuclides, such as yttrium-90 ( $\left.{ }^{90} \mathrm{Y}-\mathrm{BrE}-3,{ }^{90} \mathrm{Y}-\mathrm{m} 170\right)$ and ${ }^{131} \mathrm{I}-\mathrm{or}{ }^{90} \mathrm{Y}$-labelled L6 antibody, yielding partial or rarely complete responses. Adjuvant peripheral blood stem cells transfusion prevents myelotoxicity. 
Scintigraphic protocol guidelines suggest planar or SPECT imaging following tracer administration in the extracellular space or more often IV and rarely via an alternative route (e.g. intraperitoneally).

The higher PPV and NPV for anti-CEA-MAb SPECT as compared to mammography (100\% vs $91 \%$ and $78 \%-80 \%$ vs $25 \%$, respectively) allows for prompt biopsy or lumpectomy in MAb-positive lesions. High scintigraphic yield has also been reported for $99 \mathrm{mTc}-$ or ${ }^{111} \mathrm{In}-$ labelled $\mathrm{m} 170$ with $90 \%$ sensitivity, 93\% specificity and $92 \%$ accuracy concerning the detection of both primary and metastatic breast cancer lesions measuring less than $1 \mathrm{~cm}$ in diameter [McEwan et al., 1994]. Similar results for breast cancer detection have been shown by the use of satumomab (OncoScint, Cytogen Corp, Princeton, NJ USA), which consists of 2 mg of B72.3 MAb labelled with 111In [Nabi., 1997, Khalkhali I et al., 2001].

Overall, suggested applications of the technique do not mainly aim at diagnosing the primary tumor, but at identifying regional lymph node spread and distant metastases (bone and soft tissue), which are not otherwise visualized during pre-operative staging and at post-treatment follow-up.

\subsection{Receptor imaging}

Another radiopharmaceutical category of potential interest for imaging breast lesions comprises substances with high affinity for receptors. Receptor imaging may be applied in the diagnosis, staging, restaging, response to therapy and prognosis of breast cancer patients. Radiolabelled estradiol has been under investigation in vivo by traditional scintiscan (with 16-a,17-b-iodo-estradiol- 123IE2) and by PET. In patients with suspected breast cancer, it has shown $\geq 66 \%$ sensitivity. Nevertheless, differential diagnosis of a lesion's benign or malignant nature is difficult to be based solely on this technique, mainly because fibrocystic breast disease is also characterized by ER expression [Scheidauer et al., 1991, Rijks et al., 1996].

An interesting alternative approach utilizes radiolabelled somatostatin analogues, e.g. ${ }^{111} \mathrm{In}-$ pentetreotide. Upon investigating 52 breast cancer patients, somatostatin receptor expression has been reported to reach $85 \%$ in ductal and $56 \%$ in lobular histologies; a total of $75 \%$ detection rate regarding the primary lesion, but only $30 \%$ sensitivity for axillary lymph node status. Overall, despite the in vivo breast cancer somatostatin receptor depiction, the method is inferior to the use of traditional $99 \mathrm{mTc}$-labelled scintimammographic agents, owing to comparatively unfavorable dosimetry and cost-effectiveness [Van Eijck et al., 1994].

\subsection{Other molecular metabolic imaging modalities: positron emission tomography (PET)}

Initial PET studies on breast cancer were performed by Beany and colleagues in 1984. They demonstrated that breast tumors sustain higher perfusion than normal tissues and that despite the increased total oxygen consumption by the neoplastic tissue, oxygen extraction within the tumor is significantly decreased compared to normal tissues. Later on Mintun and colleagues described the visualization of primary tumors and a great percentage of lymh node invasion by the IV injection of steroid hormones labelled with positron-emitting nuclides, specifically ${ }^{18} \mathrm{~F}-16$-a fluoroestradiol (FES). Hormone receptor imaging constitutes a 
major functional approach of PET on breast cancer research. A subsequent study revealed $93 \%$ sensitivity for ${ }^{18} \mathrm{~F}-\mathrm{a}-\mathrm{FES}$ in the detection of the primary tumor, metastases or relapse. At the same time, clearly decreased radiotracer lesion accumulation was observed in patients receiving anti-estrogen treatment. Thus, the ability to estimate and evaluate ${ }^{18} \mathrm{~F}-\mathrm{a}-\mathrm{FES}$ uptake highlights the important role of PET on assessing breast cancer patients' response to endocrine treatment [Flanagan et al., 1996]. On the contrary, frustrating were the first attempts to depict progestin receptors (PgR) using fluoro-16a-ethyl-19-norprogesterone (FENP) labelled with ${ }^{18} \mathrm{~F}$. According to Dehdashti and colleagues (1991), the inherent radiotracer disadvantage is its non-specific uptake resulting in background uptake to the skeleton, normal mammary tissue and blood circulation. Other interesting PET radiotracers that may eventually allow for in vivo breast tumor characterization, comprise carbon-11 methionine $\left({ }^{11} \mathrm{C}-\mathrm{MET}\right)$ as a tumor protein metabolism indicator; ${ }^{11} \mathrm{C}$-thymidine or the most promising ${ }^{18} \mathrm{~F}$-fluoro-L-thymidine (FLT) as markers for cellular proliferation; ${ }^{64} \mathrm{Cu}$-labelled peptide agonists of alphavbeta3 integrin as possible markers for angiogenesis; and $18 \mathrm{~F}$ fluoromisonidazole as a marker for tumor hypoxia [Khalkhali et al., 2001, Chen et al., 2004]. PET studies retain the major advantage of true quantification of the radiotracer distribution.

The most widely used radiopharmaceutical in clinical PET is ${ }^{18} \mathrm{~F}-\mathrm{FDG}$, a tracer focusing on the study of tumor glucose metabolism. Protocol guidelines indicate the IV administration of $370 \mathrm{MBq}$ of the tracer to a fasting patient (blood Glu< 200mg/dL) with concurrent hydration and imaging after 60-180 min.

${ }^{18}$ F-FDG-PET applications in breast cancer patients have attempted detection, staging, and monitoring treatment response. According to a large series, the sensitivity for detecting tumors less than $1 \mathrm{~cm}$ is reported to be $57 \%$, compared to $91 \%$ for tumors larger than $1 \mathrm{~cm}$ [Avril $\mathrm{N}$ et al., 2000]. The sensitivity for detecting carcinoma in situ appears even lower at $25 \%$. A significantly higher false-negative rate has been observed in infiltrating lobular carcinoma (ILC) compared to IDC ( $65 \%$ vs $24 \%$, respectively), possibly due to a higher metabolic activity associated with poor prognosis. The specificity of FDG-PET in differentiating benign from malignant lesions approaches $90 \%$ in most of the studies, with the false positive results mostly attributable to inflammatory conditions. Overall sensitivity in the detection of the primary tumor has been reported to reach $80 \%-100 \%$ and specificity $75 \%-100 \%$. The verified prognostic significance of FDG uptake in the primary tumor has yet to be clarified with reference to the driving biochemical mechanisms evoking enhanced glucose metabolism. Yet, based on various research reports, its proven accuracy in detecting the primary tumor and axillary staging, does not surpass its most important current clinical application, i.e. the detection and definition of the extent of recurrent or metastatic breast cancer and monitoring response to treatment. FDG-PET is complementary to conventional staging methods in terms of higher sensitivity in identifying metastatic nodal and lytic (or mixed) bone lesions (95\% sensitivity and specificity vs. $93 \%$ sensitivity and $79 \%$ specificity by conventional imaging). Regarding distant metastases, PET appears to be more accurate compared to conventional staging modalities, with the exception of brain and osteoblastic bone metastases. Nevertheless, its sensitivity and specificity ranging from $57 \%$ to $100 \%$ and $66 \%$ to $100 \%$, respectively in various series, PET cannot be a substitute for traditional staging by computed tomography (CT) and bone scintigraphy [Eubank WB et al., 2005]. The evaluation and follow-up of the response of metastases and locally advanced disease to treatment consists the mainstay of clinical PET in breast cancer. Precocious metabolic response, as compared to the delayed tumor size reduction, is demonstrated by FDG-PET, 
thus permitting earlier assessment of response to neo-adjuvant chemotherapy administered in locally advanced disease (after 1 or 2 cycles instead of 3 to 4 required by conventional morphological imaging modalities). This early metabolic amendment potentially indicates cancer cell resistance to apoptosis [Eubank et al., 2005].

\subsection{Developing horizons}

Small tumor size is perhaps the most significant limiting factor of conventional planar scintimammography. The development of small field-of-view, dedicated breast $\gamma$-cameras with high-resolution CdZnTe (CZT) detectors seems to contribute greatly to increasing the diagnostic accuracy of the modality even for lesions below the 1-cm range [Spanu et al., 2008, 2009].

Limitations of FDG uptake including small tumor size, increased breast density, more welldifferentiated histologic subtypes (tubular carcinoma and CIS) and lobular carcinomas, have urged for technological improvements. The spatial resolution has been further enhanced with the introduction of the hybrid PET/CT scanner, which shows higher sensitivity and specificity than either PET or CT used separately.

Dynamic contrast-enhanced CT (DCECT) can measure the regional blood flow and volume along with mean transit time of blood through the capillaries and thus tumor perfusion. Combined FDG-PET/DCECT can assess not only tumor glucose metabolism, but also tumor vascularity.

These two parameters can be used in the differential diagnosis between benign and malignant lesions, assessment of tumor aggressiveness and prognosis, localisation of residual disease, treatment selection and follow-up, assessment of response to treatment and radiotherapy planning.

Furthermore, since PET using $\mathrm{H}_{2}{ }^{15} \mathrm{O}$ for tumor perfusion evaluation is not readily available, the method has not entered clinical practice. Contrast-enhanced dynamic MRI and FDG-PET may obtain similar results, which seem advantageous over DCECT due to the lack of ionizing radiation and possible reactions to the IV contrast media.

In general, the coordination of multiple methods for breast imaging is expected to improve detection, diagnosis and clinical management of breast cancer patients. Detection and diagnosis of breast cancer may be based initially on mammography. Suspicious lesions should be elucidated by SPECT or PET and MRI, in order to avoid unnecessary biopsies. While PET differentiates malignant lesions by their most enhanced metabolic activity and thus intense imaging, MRI provides the exact morphologic information about lesion site, which is required for planning biopsy or radiotherapy [Baum, 2008]. In addition, maximal benefit from PET and MRI may be obtained by spatial alignment and fusion in a single image. Difficulties resulting from the soft and easily deformed tissue may be overcome by using identical patient positioning and fiducial skin markers visible in both PET and MRI, which should be taped to predetermined locations on the skin of the breast prior to image acquisition. By this technique, it is posssible to estimate marker and nodule motions based on surface and oncometric coefficients using specific software heat transfer module.

Another approach towards a better PET/MRI image utilizes PET/CT scanner. Synchronized $\mathrm{CT}$ and PET acquisition may permit further accuracy in corresponding breast sites in 
conjunction with MRI skin markers. Positron emission mammography (PEM) is conducted by concurrent acquisition using two planar detectors and a traditional mammographic system and its role in screening or diagnosis still constitutes a field under investigation, although it does sustain the potential capability of detecting smaller and less FDG-avid tumors than the conventional whole-body PET.

Finally, other SPECT or PET assessments using proper tracers may determine selection of treatment for breast cancer patients through: a) quantification of the therapeutic target by receptor imaging, radioimmunoscintigraphy and $99 \mathrm{mTc}(\mathrm{V})$-DMSA-depicted cell proliferation in a CGRP-related neo-angiogenic background, introducing e.g. the ER (tamoxifen and letrozole), HER2 (trastuzumab [Herceptin]), EGFR (gefitinib [Iressa]) and angiogenesis factors (bevacizumab [Avastin]), considering that tumor expression may also be examined in vitro on biopsy specimens, b) identification of resistance factors, i.e. anti-HER $\mathrm{HAb}_{2} \mathrm{MAb}$ depicted $\mathrm{HER}_{2}$ expression which evokes resistance to hormone therapy, 99mTc-sestamibidepicted P-glycoprotein expression which denotes resistance to chemotherapy (doxorubicin, taxanes) and c) measurement of early response to treatment, as indicated by reduction of cell proliferation shown by ${ }^{99 \mathrm{mTc}} \mathrm{T}(\mathrm{V})$-DMSA or ${ }^{18} \mathrm{~F}-\mathrm{FLT}$.

\section{Conclusion}

In the era of rapidly developing technology, improvements in mammographic and molecular diagnostics appear promising, keeping up with the progress and corresponding demands raised by therapeutic oncology. The combination of multiple imaging methods (PET/CT, PET/MRI etc.) may concurrently evaluate both morphological and functional parameters and may directly influence the clinical management of patients bearing breast lesions, especially in recurrent or metastatic disease.

Scintimammography on its own is a simple, safe, non-invasive and widely available conventional nuclear medicine technique, which provides valuable multilevel information in the clinical management of breast lesions. The method visualizes the lesion site and also reflects specific biological and functional lesion features, including perfusion, proliferative potential, metabolic activity and receptor status. Thus, scintimammography represents not only a complementary method, but also a study of choice by applying the proper radioligand in the corresponding clinical background. It is noteworthy that the whole-body absorbed radiation dose for scintimammography is equivalent with that of mammography.

Current innovative scintimammographic findings using $99 \mathrm{mTc}(\mathrm{V})-\mathrm{DMSA}$ and $99 \mathrm{mTc}-$ sestamibi add to our understanding of the process of malignant transformation, tumor biology and further propound individualized treatment strategy by improving our ability to depict and possibly quantify the therapeutic target, identify drug remission and resistance factors, measure and predict early response and possibly apply novel therapeutics such as $188 \operatorname{Re}(\mathrm{V})$-DMSA or anti-CGRP peptides.

Hence, the clinical impact of the recent scintimammographic findings could be of great value in terms of preoperative evaluation -on a molecular basis- of the extent and the nature of a suspected breast lesion, i.e. extent of the DCIS component in a mixed DCIS+IDC, lesion multicentricity or lymph node involvement. Furthermore, possible chemoprophylactic treatment with tamoxifen, aromatase inhibitors or anti-CGRP peptides in pre-cancerous lesions, or even prophylactic administration of NSAIDs in florid 
hyperplastic lesions could be considered in patients with diffuse breast uptake patterns on $99 \mathrm{mTc}(\mathrm{V})$-DMSA. Finally, treatment with ${ }^{188} \mathrm{Re}(\mathrm{V})$-DMSA in cases of advanced disease with osseous and soft tissue metastatic spread could be considered if these lesions are depicted by breast and whole-body ${ }^{99 \mathrm{~m} T c}(\mathrm{~V})$-DMSA scintigraphy.

\section{References}

Al-Saeedi FJ. (2007). Role of $99 \mathrm{mTc}(\mathrm{V})$-DMSA in detecting tumor cell proliferation. Anal Chem Insights, Vol.2, (2007), pp.81-83, ISSN 1177-3901

Atasever, T; Gundogdu, C; Vural, G; et al. (1997). Evaluation of pentavalent Tc-99m DMSA scintigraphy in small cell and nonsmall cell lung cancers. Nuklearmedizin, Vol.36, No.7, (October 1997), pp.223-227, ISSN 0029-5566

Athanassiou, A; Pectasides, B; Pateniotis, K; et al. (1988). Immunoscintigraphy with 131Ilabelled HMFG2 and HMFG1 $\mathrm{F}\left(\mathrm{ab}^{\prime}\right)_{2}$ in the pre-operative detection of clinical and subclinical lymph node metastases in breast cancer patients. Int J Cancer, Vol.41. Suppl.S3, (1988), pp.89-95, ISSN 0020-7136

Avril, N; Rose, CA; Schelling, M; et al. (2000). Breast imaging with positron emission tomography and fluorine-18]-fluorodeoxyglucose: use and limitations. J Clin Oncol, Vol.18, No.20, (October 2000), pp.3495-3502, ISSN 0732-183X

Babbar, A; Kashyap, R; Chauhan, UP. (1991). A convenient method for the preparation of 99mTc-labelled pentavalent DMSA and its evaluation as a tumour imaging agent. $J$ Nucl Biol Med, Vol.35, No.2, (April-June 1991), pp.100-104, ISSN 0392-0208

Baum, KG. (2008). Multimodal Breast Imaging: Registration, Visualization, and Image Synthesis. PhD Dissertation, Rochester Institute of Technology, Chester F. Carlson Center for Imaging Science, 2008.

Beaney, RP; Lammertsma, AA; Jones, T; McKenzie, CG; Halnan, KE. (1984). Positron emission tomography for in vivo measurement of regional blood flow, oxygen utilisation, and blood volume in patients with breast carcinoma. Lancet, Vol.1, No.8369, (January 1984), pp.131-134, ISSN 0140-6736

Boyd, NF; Lockwood, GA; Byng, JW; et al. (1998). Mammographic densities and breast cancer risks. Cancer Epidem Biomark Prev, Vol.7, (December 1998), pp.1133-1144, ISSN 1055-9965

Casara, D; Rubella, D; Saladini, G; Masarotto, G; Calzavara, F. (1992). Significance of internal mammary lymphoscintigraphy (IML) in clinical staging and prognosis of breast cancer. Eur J Lymphology, Vol.3, (1992), pp.103-109, ISSN 0778-5569

Chen, X; Liu, S; Hou, Y; et al. (2004). MicroPET imaging of breast alphav-integrin expression with 64Cu-labelled dimeric RGD peptides. Mol Imaging Biol, Vol.6, No.5, (September-October 2004), pp.350-359, ISSN 1536-1632

Chiti, A; Maffioli, L; Castellani, M; Gasparini, M; Capri, G; Bombardieri, E. (1994). Case report: technetium-99m-hexakis-2-methoxy-isobutyl-isonitrile imaging of breast cancer and myocardial infarction in the same patient. Tumori, Vol.80, (1994), pp.480-481, ISSN 0300-8916

Dehdashti, F; McGuire, AH; Van Broclin, HF; Siegel, BA; Andriole, D; Griffeth, LK; Pomper, MG; Katzenellenbogen, JA; Welch, MJ. (1991). Assessment of 21-[18F]fluoro16aethyl-19-norprogesterone as a positron-emitting radiopharmaceutical for the detection of progestin receptors in human breast carcinomas. J Nucl Med, Vol.32, No.8, (August 1991), pp.1532-1537, ISSN 0161-5505 
Denoyer, D; Perek, N; Le Jeune, N; et al. (2004). Evidence that $99 \mathrm{mTc}-(\mathrm{V})-\mathrm{DMSA}$ uptake is mediated by $\mathrm{NaPi}$ cotransporter type III in tumour cell lines. Eur J Nucl Med Mol Imaging, Vol.31, No.1, (January 2004), pp.77-84, ISSN 1619-7070

Denoyer, D; Perek, N; Le Jeune, N; et al. (2005). Correlation between 99mTc-(V)-DMSA uptake and constitutive level of phosphorylated focal adhesion kinase in an in vitro model of cancer cell lines. Eur J Nucl Med Mol Imaging, Vol.32, No.7, (July 2005), pp.820-827, ISSN 1619-7070

De Cicco, C; Cremonesi, M; Chinol, M; Bartolomei, M; Pizzamiglio, M; Leonardi, L; Fiorenza, M; Paganelli, G. (1997). Optimization of axillary lymphoscintigraphy to detect the sentinel node in breast cancer. Tumori, Vol.83, No.2, (March-April 1997), pp.539-541, ISSN 0300-8916

Eubank, WB; Mankoff DA. (2005). Evolving Role of Positron Emission Tomography in Breast Cancer Imaging. Semin Nucl Med, Vol.35, No.2, (April 2005), pp.84-99, ISSN 0001-2998

Flanagan, FL; Dehdashti, F; Mortimer, JE; Siegel, BA; Jonson, S; Welch, MJ. (1996). PET assessment of response to tamoxifen therapy in patients with metastatic breast cancer. J Nucl Med, Vol.37, (1996), pp.99P, ISSN 0161-5505

Goldenberg, DM; Nabi HA. (1999). Breast cancer imaging with radiolabelled antibodies. Semin Nucl Med, Vol.29, No.1, (January 1999), pp.41-48, ISSN 0001-2998

Harris, RE; Beebe-Donk, J; Alshafie, GA. (2006). Reduction in the risk of human breast cancer by selective cyclooxygenase-2 (COX-2) inhibitors. BMC Cancer, Vol.6, (January 2006), pp.27, ISSN 1471-2407

Hirano, T; Otake, H; Yoshida, I; Endo, K. (1995). Primary lung cancer SPECT imaging with pentavalent technetium-99m-DMSA. J Nucl Med, Vol.36, No.2, (February 1995), pp.202-207, ISSN 0161-5505

Hirano, T; Otake, H; Kazama, K; et al. (1997). Technetium-99m(V)-DMSA and thallium-201 in brain tumor imaging: correlation with histology and malignant grade. J Nucl Med, Vol.38, No.11, (November 1997), pp.1741-1749, ISSN 0161-5505

Le Jeune, N.; Perek, N.; Denoyer, D. \& Dubois, F. (2005). Study of monoglutathionyl conjugates TC-99M-sestamibi and TC-99M-tetrofosmin transport mediated by the multidrug resistance-associated protein isoform 1 in glioma cells. Cancer Biother Radiopharm, Vol.20, No.3, (June 2005), pp.249-259, ISSN 1084-9785

Kairemo, KJ. (1990). Immunolymphoscintigraphy with Tc-99m-labelled monoclonal antibody (BW 431/26) reacting with carcinoembryonic antigen in breast cancer. Cancer Research, Vol.50, Suppl.3 (1990), pp.949s-954s, ISSN 0008-5472

Kashyap, R; Babbar, A; Sahai, I; et al. (1992). Tc-99m(V) DMSA imaging. A new approach to studying metastases from breast carcinoma. Clin Nucl Med, Vol.17, No.2, (February 1992), pp.119-122, ISSN 0363-9762

Khalkhali, I; Maublant, JC; Goldsmith, SJ. (2001). Nuclear oncology. Diagnosis and therapy. $1^{\text {st }}$ edn. Philadelphia: Lippincott Williams and Wilkins; (2001).

Kiratli, H; Kiratli, PO; Ercan, MT. (1998). Scintigraphic evaluation of tumors metastatic to the choroid using technetium-99m(V)-dimercaptosuccinic acid. Jpn J Ophthalmol, Vol.42, (1998), pp.60-65, ISSN 0021-5155 
Krag, DN; Weaver, DL; Alex, JC; Fairbank, JT. (1993). Surgical resection and radiolocalization of the sentinel lymph node in breast cancer using a gamma probe. Surg Oncol, Vol.2, No.6, (December 1993), pp.335-339, ISSN 0960-7404

Lam, AS; Kettle, AG; O'Doherty, MJ; et al. (1997). Pentavalent 99mTc-DMSA imaging in patients with bone metastases. Nucl Med Commun, Vol.18, No.10, (March 1997), pp.907-914, ISSN 0143-3636

Lee, VW; Sax, EJ; McAneny, DB; Pollack, S; Blanchard, RA; Beazley, RM; Kavanah, MT; Ward, RJ. (1993). A complementary role for thallium 201 scintigraphy with mammography in the diagnosis of breast cancer. J Nucl Med, Vol.34, No.12 (December 1993), pp.2095-2100, ISSN 0161-5505

Lind, P; Smola, MG; Lechner, P; et al. (1991). The immunoscintigraphic use of Tc-99mlabelled monoclonal anti-CEA antibodies (BW 431/26) in patients with suspected primary, recurrent and metastatic breast cancer. Int J Cancer, Vol.47, No.6, (April 1991), pp.865-869, ISSN 0020-7136

McEwan, AJB; MacLean, GD; Goldberg, L; et al. (1994). Evaluating radioimmunoscintigraphy in patients with breast cancer (abstr.). Eur J Nucl Med, Vol.21, (1994), P748, ISSN 1619-7070

Nabi, HA. (1997). Antibody imaging in breast cancer. Semin Nucl Med, Vol.27, No.1, (January 1997), pp.30-39, ISSN 0001-2998

Ohta, H; Yamamoto, K; Endo, K; et al. (1984). A new imaging agent for medullary carcinoma of the thyroid. J Nucl Med, Vol.25, No.3, (March 1984), pp.323-325, ISSN 0161-5505

Papantoniou, V; Christodoulidou, J; Papadaki, E; Valotassiou, V; Stipsanelli, A; Louvrou, A; Lazaris, D; Sotiropoulou, M; Pampouras, G; Keramopoulos, A; Michalas, S; Zerva,

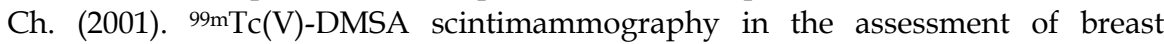
lesions: comparative study with 99mTc-MIBI. Eur J Nucl Med, Vol.28. No.7, (July 2001), pp.923-928, ISSN 1619-7070

Papantoniou, V; Christodoulidou, J; Papadaki, E; Valotassiou, V; Souvatzoglou, M; et al. (2002). Uptake and washout of 99mTcV-dimercaptosuccinic acid and 99mTc-sestamibi in the assessment of histological type and grade in breast cancer. Nucl Med Commun, Vol.23. No.5, (May 2002), pp.461-467, ISSN 0143-3636

Papantoniou, VJ; Souvatzoglou, MA; Valotassiou, VJ; Louvrou, AN; Ambela, C; et al. (2004). Relationship of cell proliferation (Ki-67) to $99 \mathrm{mTc}-(\mathrm{V}) \mathrm{DMSA}$ uptake in breast cancer. Breast Cancer Res, Vol.6, No.2, (2004), pp.R56-R62, ISSN 1465-5411

Papantoniou, V; Tsiouris, S; Mainta, E; Valotassiou, V; Souvatzoglou, M; et al. (2005a). Imaging in situ breast carcinoma (with or without an invasive component) with technetium-99m pentavalent dimercaptosuccinic acid and technetium-99m 2methoxy isobutyl isonitrile scintimammography. Breast Cancer Res, Vol.7, No.1, (January 2005), pp.R33-R45, ISSN 1465-5411

Papantoniou, V; Tsiouris S. (2005b). In vitro verification of the correlation of in vivo 99mTc(V)-DMSA uptake with cellular proliferation rate. Eur J Nucl Med Mol Imaging, Vol.32. No.10, (September 2005), pp.1240-1241, ISSN 1619-7070

Papantoniou, V; Ptohis, N; Tsiouris, S; (2006a). Diffuse tracer uptake in scintimammography: not as nonspecific or benign as originally believed? $\mathrm{J} \mathrm{Nucl}$ Med, Vol.47, No.3, (March 2006), pp.554-555, ISSN 0161-5505 
Papantoniou, V; Tsiouris, S; Koutsikos, J; Sotiropoulou, M; Mainta, E; Lazaris, D; Valsamaki, P; Melissinou, M; Zerva, Ch; Antsaklis, A. (2006b). Scintimammographic detection of usual ductal breast hyperplasia with increased proliferation rate at risk for malignancy. Nucl Med Commun, Vol.27. No.11, (January 2006), pp.911-917, ISSN 0143-3636

Papantoniou, V; Tsiouris, S; Sotiropoulou, M; Valsamaki, P; Koutsikos, J; Ptohis, N; Dimitrakakis, C; Sotiropoulou, E; Melissinou, M; Nakopoulou, L; Antsaklis, A; Zerva, Ch. (2007). The Potential Role of Calcitonin Gene-Related Peptide (CGRP) in Breast Carcinogenesis and Its Correlation With $99 \mathrm{mTc}(\mathrm{V})-\mathrm{DMSA}$ Scintimammography. Am J Clin Oncol, Vol.30. No.4, (August 2007), pp.420-427, ISSN 0277-3732

Papantoniou, V; Sotiropoulou, E; Valsamaki, P; Tsaroucha, A; Sotiropoulou, M; Ptohis, N; Stipsanelli, A; Dimitrakakis, K; Marinopoulos, S; Tsiouris, S; Antsaklis A. (2010a). Reduced uptake of the proliferation-seeking radiotracer technetium-99m-labelled pentavalent dimercaptosuccinic acid in a 47-year-old woman with severe breast epithelial hyperplasia taking ibuprofen: a case report. Journal of Medical Case Reports, Vol.4, (March 2010), pp89, doi:10.1186/1752-1947-5-598

Papantoniou V; Tsaroucha A; Valsamaki P; Fothiadaki A; Karianos T; Archontaki A; Marinopoulos S; Pappas V; Syrgiannis K; Liotsou T; Sotiropoulou M; Tsiouris S; Stipsanelli A; Dimitrakakis C; Antsaklis A. (2010b). Mixed invasive ductal associated with in situ, but not pure invasive breast carcinoma, correlates with neoangiogenesis, increased breast density, calcitonin gene related peptide positivity and cell proliferation seeking radiotracer $99 \mathrm{mTc}(\mathrm{V}) \mathrm{DMSA}$ uptake. Eur J Nucl Med Mol Imaging, Vol.37, Suppl.2, (October 2010), pp.417, ISSN 1619-7070

Papantoniou, V; Tsaroucha, A; Valsamaki, P; Tsiouris, S; Sotiropoulou, E; Karianos, T; Marinopoulos, S; Fothiadaki, A; Sotiropoulou, M; Archontaki, A; Syrgiannis, K; Dimitrakakis, K; Antsaklis (2010c). Ibuprofen induces reduction of the proliferation-seeking radiotracer $99 \mathrm{mTc}(\mathrm{V})$-DMSA uptake in severe epithelial breast hyperplasia without atypia. Mol Imaging, Vol.9. No.5, (October 2010), pp.233-236, ISSN 1535-3508

Papantoniou, V; Sotiropoulou, E; Valsamaki, P; Tsaroucha, A; Sotiropoulou, M; et al. (2011a). Breast density, scintimammographic ${ }^{99} \mathrm{mTc}(\mathrm{V}) \mathrm{DMSA}$ uptake and calcitonin gene related peptide (CGRP) expression in mixed invasive ductal associated with extensive in situ ductal carcinoma (IDC+DCIS) and pure invasive ductal carcinoma (IDC): correlation with estrogen receptor (ER) status, proliferation index Ki-67 and histological grade. Breast Cancer, Vol.18. No.4, (October 2011), pp.286-291, ISSN 1340-6868

Papantoniou, V; Valsamaki, P; Sotiropoulou, E; Tsaroucha, A; Tsiouris, S; Sotiropoulou, M; Marinopoulos, S; Kounadi, E; Karianos, T; Fothiadaki, A; Archontaki, A; Syrgiannis, K; Ptohis, N; Makris, N; Limouris, G; A. (2011b). Increased Breast Density Correlates with the Proliferation-Seeking Radiotracer 99mTc(V)-DMSA uptake in Florid Epithelial Hyperplasia and in Mixed Ductal Carcinoma In Situ with Invasive Ductal Carcinoma but not in Pure Invasive Ductal Carcinoma and in 
Mild Epithelial Hyperplasia. Mol Imaging, Vol.1. No.10, (October 2011), pp.370-376, ISSN 1535-3508

Piccolo, S; Lastoria, S; Mainolfi, C; Muto, P; Bazzicalupo, L; Salvatore, M. (1995). Technetium 99m methylene diphosphonate scintimammography to image primary breast cancer. J Nucl Med, Vol.36, No.5, (May 1995), pp.718-724, ISSN 0161-5505

Rijks, LJM; Van Tienhoven, G; Noorduyin, LA; De Bruin, K; Boer, GJ; Janssen, AGM; Van Royen, EA. Imaging of primary breast cancer with the estrogen receptor specific radioligand Z-[I-123]MIVE. Eur J Nucl Med, Vol.23, (1996), pp.1096, ISSN 1619-7070

Rijks, LJM; Bakker, PJM; Veenhof, CHN; Boer, GJ; De Bruin, K; Janssen, AGM; Van Royen, EA. (1996). Imaging of recurrent or metastatic breast cancer with the estrogen receptor specific ligand Z-[I-123]MIVE. Eur J Nucl Med, Vol.23, (1996), pp.1226, ISSN 1619-7070

Scheidhauer, K; Muller, S; Smolarz, K; Brautigam, P; Briele, B. (1991). Tumour scintigraphy using ${ }^{123}$ I-labelled estradiol in breast cancer-receptor scintigraphy. Nuklearmedizin, Vol.30, No.3, (1991), pp.84-99, ISSN 0029-5566

Spanu, A; Chessa, F; Meloni, GB; Sanna, D; Cottu, P; Manca, A; Nuvoli, S; Madeddu, G. (2008). The role of planar scintimammography with high-resolution dedicated breast camera in the diagnosis of primary breast cancer. Clin Nucl Med, Vol.33, No.11 (November 2008), pp.739-742, ISSN 1536-0229

Spanu, A; Chessa, F; Sanna, D; Cottu, P; Manca, A; Nuvoli, S; Madeddu, G. (2009). Scintimammography with a high resolution dedicated breast camera in comparison with SPECT/CT in primary breast cancer detection. Q J Nucl Med Mol Imaging, Vol.53, No.3 (June 2009), pp.271-280, ISSN 1824-4661

Stipsanelli, E; Valsamaki P. (2005). Monoclonal antibodies: old and new trends in breast cancer imaging and therapeutic approach. Hell J Nucl Med, Vol.8. No.2, (July 2005), pp.103-108, ISSN 1790-5427

Tamimi, RM; Byrne, C; Colditz, GA; Hankinson, SE. (2007). Endogenous hormone levels, mammographic density and subsequent risk of breast cancer in postmenopausal women. J Natl Cancer Inst, Vol.99, No.15, (August 2007), pp.1178 -1187, ISSN 00278874

Thompson, C; Stacker, S; Salehi, N. (1984). Immunoscintigraphy for the detection of lymph node metastases from breast cancer. Lancet, Vol.324, No.8414 (December 1984), pp.1245-1247, ISSN 0140-6736

Toda, M; Suzuki, T; Hosono, K; et al. (2008). Neuronal system-dependent facilitation of tumor angiogenesis and tumor growth by calcitonin gene-related peptide. Proc Natl Acad Sci U S A, Vol.105, No.36, (September 2008), pp.13550-13555, ISSN 0027-8424

Tsiouris, S.; Pirmettis, I.; Chatzipanagiotou, T.; Ptohis, N. \& Papantoniou, V. (2007). Pentavalent technetium-99m dimercaptosuccinic acid [99mTc-(V)DMSA] brain scintitomography--a plausible non-invasive depicter of glioblastoma proliferation and therapy response. J Neurooncol, Vol.85, No.3, (December 2007), pp.291-295, ISSN 0167594X

Uren, RF; Howman-Giles, RB; Thompson, JF; Malouf, D; Ramsey-Stewart, G; Niesche, FW; Renwick, SB. (1995). Mammary lymphoscintigraphy in breast cancer. J Nucl Med, Vol.36, No.10, (October 1995), pp.1775-1780, ISSN 0161-5505 
Van Eijck, CH; Krenning, EP; Bootsma, A; Oei, HY; Van Pel, R; Lindemans, J; Jeekel, J; Reubi, JC; Lamberts, SWJ. (1994). Somatostatin-receptor scintigraphy in primary breast cancer. Lancet, Vol.343, (1994), pp.640-643, ISSN 0140-6736

Waxman, AD; Ramanna, L; Brachman, MB. (1989). Thallium scintigraphy in primary carcinoma of the breast: evaluation of primary and axillary metastasis. J Nucl Med, Vol.30, (1989), pp.844-848, ISSN 0161-5505 


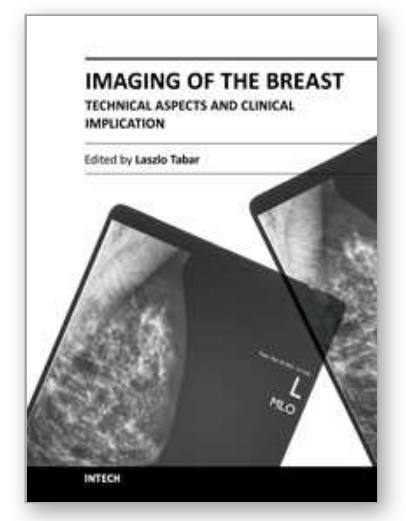

\author{
Imaging of the Breast - Technical Aspects and Clinical Implication \\ Edited by Dr. Laszlo Tabar
}

ISBN 978-953-51-0284-7

Hard cover, 224 pages

Publisher InTech

Published online 16, March, 2012

Published in print edition March, 2012

Early detection of breast cancer combined with targeted therapy offers the best outcome for breast cancer patients. This volume deal with a wide range of new technical innovations for improving breast cancer detection, diagnosis and therapy. There is a special focus on improvements in mammographic image quality, image analysis, magnetic resonance imaging of the breast and molecular imaging. A chapter on targeted therapy explores the option of less radical postoperative therapy for women with early, screen-detected breast cancers.

\title{
How to reference
}

In order to correctly reference this scholarly work, feel free to copy and paste the following:

Vassilios Papantoniou, Pipitsa Valsamaki and Spyridon Tsiouris (2012). Scintimammography - Molecular Imaging: Value and New Perspectives with 99mTc(V)-DMSA, Imaging of the Breast - Technical Aspects and Clinical Implication, Dr. Laszlo Tabar (Ed.), ISBN: 978-953-51-0284-7, InTech, Available from: http://www.intechopen.com/books/imaging-of-the-breast-technical-aspects-and-clinicalimplication/scintimammography-molecular-imaging-value-and-perspectives

\section{INTECH}

open science | open minds

\section{InTech Europe}

University Campus STeP Ri Slavka Krautzeka 83/A 51000 Rijeka, Croatia Phone: +385 (51) 770447

Fax: +385 (51) 686166 www.intechopen.com

\section{InTech China}

Unit 405, Office Block, Hotel Equatorial Shanghai No.65, Yan An Road (West), Shanghai, 200040, China 中国上海市延安西路65号上海国际贵都大饭店办公楼405单元 Phone: +86-21-62489820

Fax: +86-21-62489821 
(C) 2012 The Author(s). Licensee IntechOpen. This is an open access article distributed under the terms of the Creative Commons Attribution 3.0 License, which permits unrestricted use, distribution, and reproduction in any medium, provided the original work is properly cited. 